\title{
Seed soaking with Bacillus sp. strain HX-2 alleviates negative effects of drought stress on maize seedlings
}

\author{
Heqin $\mathrm{Li}^{1}$, Yanming Zhao', and Xuwen Jiang ${ }^{*}$ \\ 'Qingdao Agricultural University, College of Agronomy, No. 700 Changcheng Road, Chengyang District, Qingdao, Shandong 266109, \\ China. "Corresponding author (mjxw888@163.com).
}

Received: 1 October 2018; Accepted: 23 February 2019; doi:10.4067/S0718-58392019000300396

\begin{abstract}
Drought, one of the most detrimental environmental factors for agricultural production all over the world, severely represses plant survival and productivity of crops. Microbial technology plays a prominent part in improving drought resistance of crops. Here, endophytic bacterium Bacillus megaterium strain HX-2 was isolated from healthy leaves of Agastache rugosa (Fisch. \& C.A. Mey.) Kuntze; its drought tolerance level and growth promoting characteristics were carried out in vivo, and the effects of the bacterium on morphological, physiological and biochemical variables of maize (Zea mays L.) seedling under drought stress were investigated in a pot experiment. As a result, B. megaterium strain HX-2 had $15 \%$ tolerance to polyethylene glycol 6000 , produced indoleacetic acid and dissolved phosphate. After inoculation with strain HX-2, plant height, root length, plant biomass, root:shoot ratio, root activity, leaf relative water content, proline content, plant $\mathrm{P}$ content, and enzyme activities including superoxide dismutase, catalase, peroxidase and ascorbate peroxidase increased considerably by $7.69 \%-42.9 \%$, whereas electrolyte leakage and malondialdehyde content declined significantly by $28.17 \%-42.38 \%$ relative to drought stress. These changes suggested that strain HX-2 was able to alleviate negative effects of drought stress on plants by producing indoleacetic acid and dissolving phosphate to improve the antioxidant system of plants. This study will provide theoretical reference for cultivation of maize under drought stress.
\end{abstract}

Key words: Antioxidant system, Bacillus megaterium, drought stress, indoleacetic acid production, phosphate solubilization property, Zea mays.

\section{INTRODUCTION}

Maize (Zea mays L.) is a very important crop used all over the world. In addition to its role as food, maize is also a crucial resource for economic and industrial applications, such as fuel and animal feed. However, drought, an important abiotic stress factor, seriously damages maize growth and leads to loss in productivity. From statistics, the maize yield reduction was 39.3\% between 1980 and 2015 (Daryanto et al., 2016). In China, arid and semiarid lands including northern and northwestern China, occupy about half the entire land area of the country. Every year, drought often results in drastic reductions in maize yield (Sun et al., 2017). It was reported that $33 \%$ of maize yield loss was caused by drought in Northeast China (Zhang, 2004).

Some strategies, such as breeding drought-tolerant varieties and optimizing cultivation technology, have been used for improving crop tolerance to drought stress. Due to their extensive potentiality in enhancing crop production and food safety, microbial technology has become an effective way to alleviate the current problem (Mahanty et al., 2016). For examples, maize seedlings inoculated with Bacillus spp. could increase the tolerance to drought stress (Sandhya et al., 2011). Pseudomonas spp. can improve drought resistance of maize plants (Vurukonda et al., 2016). Endophyte, one of 
the important sources of such microorganisms, is a bacterial/actinomycete/fungal microorganism. It colonizes inter- and/ or intra-cellularly inside the healthy tissues of the host plant during the whole or part of life cycle, and causes no apparent symptoms of disease. In all tissues of plant, including leaves, stems, roots, flowers and fruits, endophytes are ubiquitous. Earlier studies have shown that endophytes, especial endophytic bacteria play a very important role in improving plant growth by various mechanisms, such as production of siderophores, indole-3-acetic acid (IAA) and 1-aminocyclopropane1-carboxylic acid (ACC) deaminase, or solubilization of phosphate (Ryan et al., 2008; Zhang et al., 2011; Cedeño-García et al., 2018). Bacillus, Pseudomonas, Pantoea, among others, have been isolated from wheat, potato, rice (Feng et al., 2006; Andreote et al., 2009; Egorshina et al., 2012), and these endophytic bacteria have the function of promoting growth. Moreover, endophytic bacteria have been paid more attention to improve the efficiency of phytoremediation (Rajkumar et al., 2009). Therefore, research on endophytes has become a hot spot (Devi and Momota, 2015).

Bacillus megaterium strain HX-2, an endophytic bacterium, was isolated from healthy leaves of Agastache rugosa (Fisch. \& C.A. Mey.) Kuntze. In this study, polyethylene glycol 6000 (PEG6000) was used to simulate drought stress, drought tolerance, indole-3-acetic acid (IAA) production and phosphate solubilization property of the bacteria were examined. The effects of strain HX-2 on the maize seedlings growth under drought stress were investigated using a pot experiment. Our objective was to evaluate the ability to improve maize seedling growth under drought stress and to provide theoretical reference for drought resistant culture techniques of maize.

\section{MATERIALS AND METHODS}

\section{Isolation and identification of strains}

Agastache rugosa (Fisch. \& C.A. Mey.) Kuntze used for bacterial isolation was collected from Laoshan mountain of Qingdao city in China. Plant leaves were serially diluted, spread plated on beef extract peptone agar (beef extract $3.0 \mathrm{~g}$, peptone $10.0 \mathrm{~g}, \mathrm{NaCl} 5.0 \mathrm{~g}$, agar $15-25 \mathrm{~g}$ per liter) and incubated at $30{ }^{\circ} \mathrm{C}$ for $48 \mathrm{~h}$ (Amaresan et al., 2012; Ji et al., 2014). Bacterial strains were purified with repeated culturing and maintained in $15 \%(\mathrm{v} / \mathrm{v})$ glycerol at $-80{ }^{\circ} \mathrm{C}$. Potential isolates were selected on the basis of results of screening for drought tolerance, and were identified by partial $16 \mathrm{~S}$ ribosomal DNA sequence. The primers of 27F/1492R were used to PCR amplification. BLAST (Basic Local Alignment Search Tool; National Center for Biotechnology Information, U.S. National Library of Medicine, Bethesda Maryland, USA) search program was used to compare the sequence homology of nucleotides. The closely related sequences obtained were determined by the method described by Li and Jiang (2017).

\section{Screening for drought tolerance level and growth promoting characteristics of strain HX-2}

Bacillus megaterium strain HX-2 was deposited in the College of Agronomy, Qingdao Agricultural University, China. Polyethylene glycol (PEG6000) was added into $50 \mathrm{~mL}$ liquid Luria-Bertani medium (Marulanda et al., 2009), and its final concentrations were $5 \%, 10 \%, 15 \%$ and $20 \%\left(\mathrm{w} \mathrm{v}^{-1}\right)$, respectively. Then, actively growing strain $\mathrm{HX}-2$ was added into the above-mentioned medium on rotary shaker at $180 \mathrm{rpm}$ for $2 \mathrm{~d}$ at $30{ }^{\circ} \mathrm{C}$. Bacterial growth was determined as CFU mL through diluting method and coating method to count for strain HX-2, to find out drought tolerance.

King's B medium containing $100 \mathrm{mg} \mathrm{mL}^{-1}$ L-tryptophan and 0\%-20\% PEG6000 was used to screen for indole3-acetic acid (IAA) production ( $\mathrm{Li}$ and Jiang, 2017). The culture supernatants of the strain HX-2 were mixed with Salkowski reagent in the ratio of 1:1 $\left(\mathrm{v} \mathrm{v}^{-1}\right)$. The mixture with pink color indicates the production of IAA and its density was recorded at $530 \mathrm{~nm}$. Concentration of IAA produced was estimated against standard curve of IAA in the range of 0-100 $\mu \mathrm{g} \mathrm{mL}^{-1}$. Bacterial isolates were platted on bacterial organophosphorus medium containing 0\%-20\% PEG6000 for $7 \mathrm{~d}$ at $30^{\circ} \mathrm{C}$. The appearance of clear zone around bacterial colonies indicated phosphate solubilizing property. The phosphate solubilization index (SI) (Premono et al., 1995) was calculated using the formula: SI = (Colony diameter + Halo zone diameter)/Colony diameter.

\section{Pot experiment}

Seeds of hybrid maize 'Liyu35' were used. After surface-sterilization with $70 \%$ ethanol for $30 \mathrm{~s}$ and $1 \%$ sodium hypochlorite for $10 \mathrm{~min}$, seeds were thoroughly rinsed with sterile distilled water for use. In order to remove large particles of stones and debris, sand-soil (1:3) mixture was passed through a $2 \mathrm{~mm}$ sieve. Subsequently, the mixture 
was sterilized and air dried at room temperature. Then, $100 \mathrm{~g}$ sterilized mixture was packed into one plastic pot (150 $\mathrm{mL}$ ). Preliminary studies showed that water content in pots must be maintained by weighing at $15 \%-20 \%$ water content throughout the experiment with distilled water on alternate days as the well-watered, and water content in pots must be maintained by weighing at 5\%-8\% water content as the drought-stressed. The surface-sterilized seeds were soaked for $2 \mathrm{~h}$ in the bacterial cell suspension $\left(10^{8} \mathrm{CFU} \mathrm{mL}^{-1}\right)$ or in sterile water, and subsequently planted into the plastic pots at 4 $\mathrm{cm}$ depth, with four treatments as follows, three replicates, five pots per replicate. After emergence, seedlings in each pot were thinned to one plant and were put in a plant growth incubator (GXZ-380C, China) at $25^{\circ} \mathrm{C}$, and $250 \mu \mathrm{mol} \mathrm{m}^{-2} \mathrm{~s}^{-1}$ light for $16: 8 \mathrm{~h}$ photoperiod. The treatments were as follows: seeds soaked in sterile water sown in the well-watered sand-soil mixtures (CK1); seeds soaked in sterile water sown in the drought-stressed sand-soil mixtures (CK2); seeds soaked in bacterial cell suspension sown in the well-watered sand-soil mixtures (T1); and seeds soaked in bacterial cell suspension sown in the drought-stressed sand-soil mixtures (T2).

\section{Assay for plant morphological, physiological and biochemical indexes}

After $15 \mathrm{~d}$, plants were harvested and carefully rinsed with distilled water, then separated into aboveground plant tissues and roots. The plant height, root length, dry weight of seedlings were measured (Li and Jiang, 2017). The root:shoot ratio was the proportion of root biomass with respect to aboveground plant tissues biomass.

According to the method of Ghahfarokhi et al. (2015), the relative water content (RWC) of the leaf sample was estimated. The relative electrolyte leakages (EL) were determined by the method described by Voigt (2009), malondialdehyde (MDA) and proline content of leaves was determined according to the method describe by Zhu et al. (2010), root activity was determined using the method of triphenyltetrazolium chloride (TTC) (Li et al., 2015), plant P content was analyzed colorimetrically by the molybdenum blue method (Bao, 2000). About $500 \mathrm{mg}$ fresh leaf samples were homogenized in $10 \mathrm{~mL} 0.05 \mathrm{M}$ phosphate buffer (pH 7.8) solution, and centrifuged at $10000 \times \mathrm{g}$ for $10 \mathrm{~min}$ (Premono et al., 1995). Then, the supernatant was collected and stored at $4{ }^{\circ} \mathrm{C}$ for use. The enzyme activities of superoxide dismutase (SOD), catalase (CAT), peroxidase (POD) and ascorbate peroxidase (APX) were determined (Chen and Asada, 1992; Zhu et al., 2010; Ghahfarokhi et al., 2015).

\section{Statistical analysis}

Data were analyzed using ANOVA of Statistics SPSS 19.0 (IBM; Armonk, New York, USA) software, differences were compared using Duncan's multiple range test at 0.05 level.

\section{RESULTS}

According to morphological trait, a total of five bacterial strains were isolated from the leaf samples, and then all strains were initially screened for the drought tolerance. Bacterial strain HX-2 was able to grow on nutrient agar with 20\% PEG and was selected for further identification and sequence analysis. The strain HX-2 was Gram positive, rod and ovalshaped spores. Result of BLAST search of the National Center of Biotechnology Information (NCBI) and phylogenetic analysis showed that strain HX-2 shared 99.0\% sequence similarity with Bacillus megaterium (KC189946.1) (Figure 1). Therefore, the strain HX-2 was identified as Bacillus megaterium HX-2 based on 16S ribosomal DNA sequence, whose sequence was submitted to GenBank (accession number MH930825).

After shake culture for $2 \mathrm{~d}$ at $180 \mathrm{rpm}$ in the dark, drought tolerance of the endophytic bacteria strain HX-2 was found, it could tolerate higher levels of drought stress, the maximum tolerance to PEG was $15 \%$ (Figure 2). After shake culture for 7 d, IAA production of the HX-2 in the King's B medium was determined with spectrophotometer method. IAA concentration decreased with the increasing concentration of PEG6000, whose maximum value was $34.10 \mu \mathrm{gL}^{-1}$ (Figure 3). After culture on bacterial organophosphorus medium containing 0\%-20\% PEG6000 for $7 \mathrm{~d}$, the phosphate solubilization activity was detected. Transparent zone extending from the edge of the bacterial colony was shown by strain HX-2. The phosphate solubilization index (SI) decreased with the increasing concentration of PEG6000, and the maximum value was 1.3 (Figure 4). These results suggest that strain HX-2 has drought tolerance and growth promoting characteristics. 
Figure 1. Phylogenetic tree of Bacillus megaterium strain HX-2.

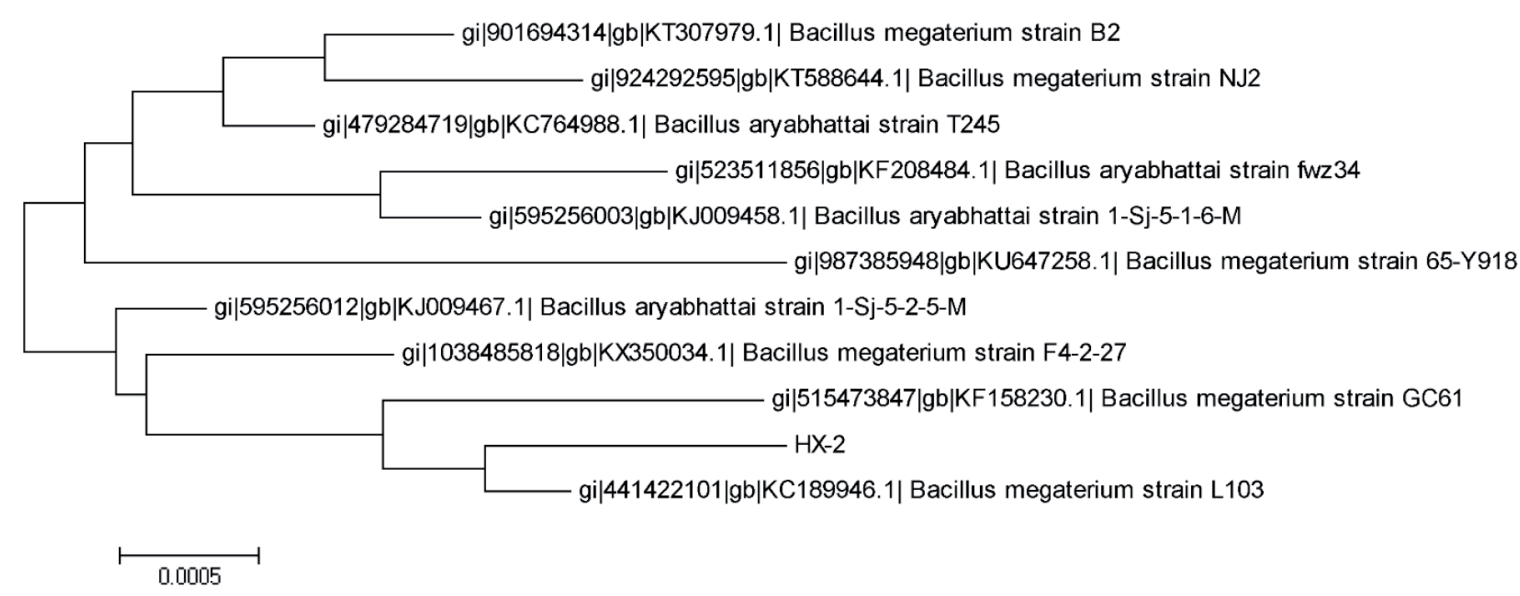

Figure 2. Effect of polyethylene glycol (PEG6000) on growth of Bacillus megaterium strain HX-2.

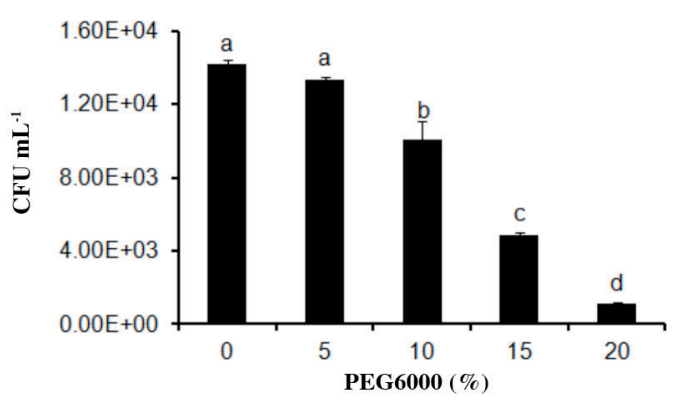

The values represent the means of data obtained in the experiment $(n=3)$. Different letters indicate significantly different values $(\mathrm{p}<0.05)$ between treatments.

Figure 3. Effect of polyethylene glycol (PEG6000) on indole-3-acetic acid (IAA) concentration from Bacillus megaterium strain HX-2.

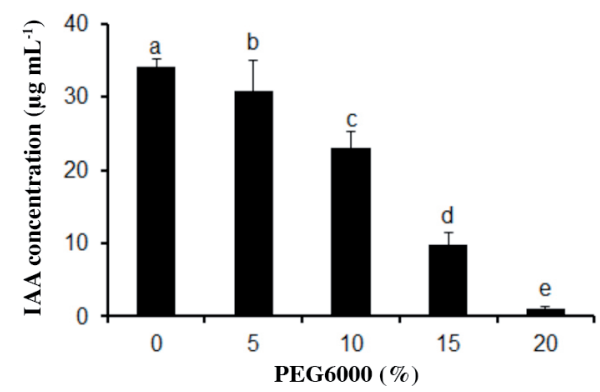

The values represent the means of data obtained in the experiment $(n=3)$. Different letters indicate significantly different values $(\mathrm{p}<0.05)$ between treatments.

Plant height, root length, dry weights of above-ground and root of maize seedlings were significantly reduced by drought stress (CK2), compared with well-watered treatment (CK1). However, under well-watered condition, seeds soaked in the strain HX-2 suspension significantly increased plant height, root length, dry weight of above-ground and root by $20.80 \%, 23.86 \%, 23.6 \%$ and $24.6 \%$; while for drought stress, increases were $26.32 \%, 32.54 \%, 32.3 \%$ and $42.9 \%$ (Table 1). Similarly, the root:shoot ratio was significantly increased by CK2, compared with CK1. And under drought stress and well-watered condition, seeds soaked in the strain HX-2 suspension significantly increased root:shoot ratio by 7.69\% and 5.88\% (Table 1). And the effects of strain HX-2 on plant height, root length, dry weights of above-ground and root of maize seedlings under drought stress were more than well-watered condition. 
Figure 4. Effect of polyethylene glycol (PEG6000) on phosphate solubilization index of Bacillus megaterium strain HX-2.

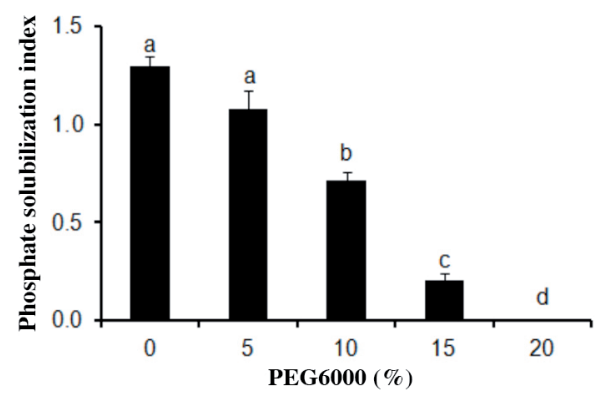

The values represent the means of data obtained in the experiment $(n=3)$. Different letters indicate significantly different values $(\mathrm{p}<0.05)$ between treatments.

Table 1. Effects of Bacillus megaterium strain HX-2 on plant height, root length, dry weight of above-ground and root of maize seedlings.

\begin{tabular}{|c|c|c|c|c|c|}
\hline Treat & $\begin{array}{l}\text { Plant } \\
\text { height }\end{array}$ & $\begin{array}{l}\text { Root } \\
\text { length }\end{array}$ & $\begin{array}{l}\text { Dry weight of } \\
\text { above-ground }\end{array}$ & $\begin{array}{l}\text { Dry weight } \\
\text { of root }\end{array}$ & $\begin{array}{l}\text { Root:shoot } \\
\text { ratio }\end{array}$ \\
\hline & \multicolumn{2}{|c|}{$\mathrm{cm}$} & \multicolumn{2}{|c|}{ mg plant $^{-1}$} & \\
\hline K1 & $6.25 \pm 0.57 b$ & $8.59 \pm 0.33 b$ & $38.6 \pm 0.9 b$ & $6.5 \pm 0.3 b$ & 0.17 \\
\hline K2 & 2.28 & 5.47 & $22.0 \pm 1.0 \mathrm{~d}$ & 5. & 0.2 \\
\hline $\mathrm{T} 1$ & $7.55 \pm 0.62 \mathrm{a}$ & $10.64 \pm$ & 47 & 8.1 & 0.18 \\
\hline $\mathrm{T} 2$ & $2.88 \pm 0.41 \mathrm{c}$ & $7.25 \pm 0.53 c$ & $29.1 \pm 0.6 \mathrm{c}$ & $8.0 \pm 0.6 \mathrm{a}$ & $0.28 \pm 0.02 \mathrm{a}$ \\
\hline
\end{tabular}

All such means which share the same letter in the column are similar otherwise differ significantly at $\mathrm{p}<0.05$. Mean values \pm standard deviation are shown $(\mathrm{n}=5)$.

CK1: Seeds soaked in sterile water sown in the well-watered sand-soil mixtures; CK2: seeds soaked in sterile water sown in the drought-stressed sand-soil mixtures; T1: seeds soaked in bacterial cell suspension sown in the well-watered sand-soil mixtures; T2: seeds soaked in bacterial cell suspension sown in the drought-stressed sand-soil mixtures.

The P content of above-ground in maize seedlings was significantly decreased by CK2, compared with CK1. Significant differences in the P content of above-ground or root in maize seedlings were found in the seeds soaked in the strain HX-2 suspension relative to unsoaked treatments. And under drought stress and well-watered condition, seeds soaked in the strain HX-2 suspension significantly increased P content by $42.10 \%$ and $38.10 \%$ in above-ground of maize seedlings, by $41.67 \%$ and $38.46 \%$ in root of maize seedlings (Figure 5).

Relative water content (RWC) was significantly reduced by CK2, compared with CK1, regardless of drought stress or well-watered condition. Effects of seeds soaked in the strain HX-2 suspension increased RWC (Table 2). Under wellwatered condition, RWC slightly increased, while drought stress, RWC significantly increased by $12.55 \%$. Similarly,

Figure 5. Effects of Bacillus megaterium strain HX-2 on P content of above-ground and root of maize seedlings.

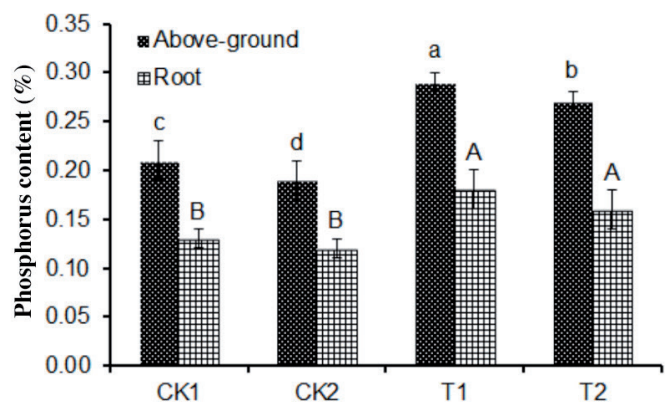

The values represent the means of data obtained in the experiment $(n=5)$. Different letters indicate significantly different values $(\mathrm{p}<0.05)$ between treatments, lower-case letters showed in above-ground and uppercase letters showed in the root.

CK1: Seeds soaked in sterile water sown in the well-watered sand-soil mixtures; CK2: seeds soaked in sterile water sown in the drought-stressed sand-soil mixtures; T1: seeds soaked in bacterial cell suspension sown in the well-watered sand-soil mixtures; T2: seeds soaked in bacterial cell suspension sown in the drought-stressed sand-soil mixtures. 
root activity of maize seedlings was significantly reduced by $67.12 \%$ under drought stress. However, root activity was improved by $24.32 \%$ by seeds soaked in the strain HX-2 suspension, compared to CK2. Meanwhile, strain HX-2 also increased root activity of maize seedlings under well-watered by $16.50 \%$.

Drought induced high EL levels, which were reduced by $28.17 \%$ by seeds soaked in the strain HX-2 suspension under drought stress (Table 2). And MDA content in leaves of drought-treated plants was $59.95 \%$ above values found in well-watered plants. Seeds soaked in the strain HX-2 suspension decreased MDA content by $42.38 \%$, but the level was still more than well-watered plants. The proline content in drought-treated plants was $56.05 \%$ more than that in wellwatered plants. After seeds soaked in the strain HX-2 suspension, proline content was significantly increased by $32.04 \%$ in drought-treated plants.

Compared with the well-watered plants, enzyme activities of SOD, POD and CAT in drought-stressed maize seedlings were significantly decreased. Nevertheless, seeds soaked in the strain HX-2 suspension increased SOD, POD and CAT activities under drought stress and well-watered condition, in drought-stressed plants were 19.37\%, 19.86\% and 10.96\%, and in well-watered plants were 5.79\%, $12.86 \%$ and 3.29\% (Table 3). Similarly, the activities of APX in drought-stressed maize seedlings significantly reduced by $12.63 \%$, seeds soaked in the strain HX-2 suspension increased the enzyme activities of APX under drought stress and well-watered conditions, some in drought-stressed plants even more than those in well-watered plants (Table 3). Therefore, the activities of SOD, POD, CAT and APX were significantly enhanced by seeds soaked in the strain HX-2 suspension.

Table 2. Effect of Bacillus megaterium strain HX-2 on relative water content (RWC), root activity, electrolyte leakage (EL), malondialdehyde (MDA) content and proline content of maize seedlings.

\begin{tabular}{lcrccc}
\hline Treatments & RWC & \multicolumn{1}{c}{$\begin{array}{c}\text { Root } \\
\text { activity }\end{array}$} & EL & $\begin{array}{c}\text { MDA } \\
\text { content }\end{array}$ & $\begin{array}{c}\text { Proline } \\
\text { content }\end{array}$ \\
\hline & $\%$ & $\mathrm{mg} \mathrm{g}^{-1} \mathrm{fw} \mathrm{h}^{-1}$ & $\%$ & $\mu \mathrm{mol} \mathrm{g}^{-1} \mathrm{fw}$ & $\mathrm{mg} \mathrm{g}^{-1} \mathrm{fw}$ \\
CK1 & $87.36 \pm 1.41 \mathrm{a}$ & $12.30 \pm 0.37 \mathrm{~b}$ & $19.79 \pm 0.43 \mathrm{c}$ & $3.97 \pm 0.19 \mathrm{c}$ & $3.14 \pm 0.49 \mathrm{c}$ \\
CK2 & $75.24 \pm 0.36 \mathrm{c}$ & $7.36 \pm 0.30 \mathrm{~d}$ & $30.80 \pm 0.33 \mathrm{a}$ & $6.35 \pm 0.18 \mathrm{a}$ & $4.90 \pm 0.31 \mathrm{~b}$ \\
T1 & $88.44 \pm 0.99 \mathrm{a}$ & $14.33 \pm 0.45 \mathrm{a}$ & $17.94 \pm 0.69 \mathrm{~d}$ & $3.23 \pm 0.16 \mathrm{~d}$ & $3.66 \pm 0.34 \mathrm{c}$ \\
T2 & $84.68 \pm 0.70 \mathrm{~b}$ & $9.15 \pm 0.22 \mathrm{c}$ & $24.03 \pm 0.56 \mathrm{~b}$ & $4.46 \pm 0.21 \mathrm{~b}$ & $6.47 \pm 0.40 \mathrm{a}$ \\
\hline
\end{tabular}

Means within column followed by different letters are significantly different at $\mathrm{p}<0.05$. Mean values \pm standard deviation are shown $(n=5)$.

fw: Fresh weight; CK1: seeds soaked in sterile water sown in the well-watered sandsoil mixtures; CK2: seeds soaked in sterile water sown in the drought-stressed sand-soil mixtures; T1: seeds soaked in bacterial cell suspension sown in the well-watered sandsoil mixtures; T2: seeds soaked in bacterial cell suspension sown in the drought-stressed sand-soil mixtures.

Table 3. Effects of Bacillus megaterium strain HX-2 on the activities of SOD, POD, CAT and APX of maize seedlings.

\begin{tabular}{lcccc}
\hline Treatments & SOD & POD & \multicolumn{1}{c}{ CAT } & APX \\
\hline & $\mathrm{U} \mathrm{g}^{-1} \mathrm{fw}$ & $-\mathrm{U} \mathrm{g}^{-1} \mathrm{fw} \mathrm{min}$ & & $\mathrm{U} \mathrm{g}^{-1} \mathrm{fw}$ \\
$\mathrm{CK} 1$ & $25.75 \pm 0.54 \mathrm{~b}$ & $16.88 \pm 0.50 \mathrm{~b}$ & $13.98 \pm 0.59 \mathrm{~b}$ & $2.14 \pm 0.23 \mathrm{bc}$ \\
$\mathrm{CK} 2$ & $20.39 \pm 0.58 \mathrm{~d}$ & $12.54 \pm 0.96 \mathrm{~d}$ & $11.13 \pm 0.50 \mathrm{~d}$ & $1.90 \pm 0.17 \mathrm{c}$ \\
$\mathrm{T} 1$ & $27.24 \pm 0.36 \mathrm{a}$ & $19.05 \pm 0.68 \mathrm{a}$ & $14.44 \pm 0.37 \mathrm{a}$ & $2.26 \pm 0.16 \mathrm{~b}$ \\
T2 & $24.34 \pm 0.41 \mathrm{c}$ & $15.03 \pm 0.57 \mathrm{c}$ & $12.35 \pm 0.43 \mathrm{c}$ & $3.67 \pm 0.22 \mathrm{a}$ \\
\hline
\end{tabular}

Means within column followed by different letters are significantly different at $\mathrm{p}<0.05$. Mean values \pm standard deviation are shown $(n=5)$.

SOD: Superoxide dismutase; POD: peroxidase; CAT: hydrogen peroxide; APX: ascorbate peroxidase; U: active unit; fw: fresh weight; CK1: seeds soaked in sterile water sown in the well-watered sand-soil mixtures; CK2: seeds soaked in sterile water sown in the drought-stressed sand-soil mixtures; T1: seeds soaked in bacterial cell suspension sown in the well-watered sand-soil mixtures; T2: seeds soaked in bacterial cell suspension sown in the drought-stressed sand-soil mixtures. 


\section{DISCUSSION}

Seeds soaked in the strain HX-2 suspension significantly increased plant height, root length, dry weight of above-ground and root, and root:shoot ratio, indicating that strain HX-2 was able to improve plant growth and alleviate drought stress negative effects on maize seedlings. In order to absorb water and promote growth, plant tries to extend the root to explore more soil volume under drought stress. Therefore, the increase of root:shoot ratio has been considered as a mechanism for plant defense drought conditions ( $\mathrm{Wu}$ and Cosgrove, 2000). The increase in root:shoot ratio could be the reason that strain HX-2 can produce indoleacetic acid, which significantly improved the growth of maize seedlings under drought stress. Previous studies also have shown IAA enabled the plants to withstand water stress (Zhao et al., 2012). In addition, microbes have been reported to mobilize nutrients to plant roots (Saia et al., 2015). In this study, strain HX-2 could dissolve $\mathrm{P}$, which provided more nutrients for plant roots to improve plant nutrition uptake and growth. This is consistent with the changes of plant morphological indexes and P content. Root activity is general indicator of root capacity for water and nutrient uptake. A decrease in root activity is harmful to the growth and development of maize seedlings. However, this phenomenon was alleviated by seeds soaked in the strain HX-2 suspension treatment. An increase in root activity is good for maize seedlings to uptake more water and nutrient uptake. The increase in root activity is consistent with the change of $\mathrm{P}$ content and the root:shoot ratio.

The leaf RWC is usually used to judge plant water status, which is considered as a relevant attribute for screening drought tolerance of crops. A decrease in RWC is harmful to the growth and development of maize seedlings. However, this phenomenon was alleviated by seeds soaked in the strain HX-2 suspension treatment. Meanwhile, strain HX-2 also increased RWC of maize seedlings under well-watered treatment. These results are in agreement with those of Sandhya et al. (2011), who reported that inoculation with Bacillus spp. increased RWC in maize under drought stress. It is thus clear that strain HX-2 may be important for maize water relation under drought stress and make the plants benefit to absorb more water to resist drought stress.

The levels of reactive oxygen species (ROS) and related products, such as hydrogen peroxide $\left(\mathrm{H}_{2} \mathrm{O}_{2}\right)$, superoxide anion $\left(\mathrm{O}^{2-}\right)$ and hydroxyl radical (.OH) are increased, and oxidative damage is induced by stress (Hyodo et al., 2017). The excess ROS resulted in the increasing MDA content and conductivity of solute leakage from plant cells, which were considered as characteristic of membrane lipid peroxidation (Anjum et al., 2011). Lipid peroxidation causes damaged membrane function, decreased fluidity, and inactivation of membrane-bound receptors and enzymes. Electrolyte leakage is regarded as a reliable indicator of membrane injury in response to various kinds of stresses, the extent of membrane damage can be evaluated by EL. However, natural selection has made plants maintaining a wider range of defense against environmental stress through antioxidant enzymes. For examples, $\mathrm{SOD}$ catalyses the dismutation of $\mathrm{O}^{2-}$ to $\mathrm{H}_{2} \mathrm{O}_{2}$ and $\mathrm{O}_{2}$, while $\mathrm{POD}$ and CAT scavenges $\mathrm{H}_{2} \mathrm{O}_{2}$, and APX is a $\mathrm{H}_{2} \mathrm{O}_{2}$-scavenging enzyme that is indispensable to protect chloroplasts and other cell constituents from damage by $\mathrm{H}_{2} \mathrm{O}_{2}$ and $\mathrm{OH}$. In this study, the level of EL and MDA content were significantly increased by drought stress, indicating the membrane of maize seedlings was damaged. However, this phenomenon was alleviated by inoculation with strain HX-2 treatment, which increased the activities of SOD, POD, CAT and APX and reduced the level of EL and the MDA content. SOD, POD, CAT and APX showed significant rises in activity with the strain HX-2 treatment, signifying strain HX-2 likely role in improving antioxidative defense under drought stress.

Additionally, proline is excellent osmolyte to stabilize sub-cellular structures and free radical scavenger to quench single $\mathrm{O}^{2-}$ or to react directly with $\mathrm{OH}$ (Siripornadulsil et al., 2002; Filippou et al., 2013). Under stress, proline accumulation may be due to increased synthesis and decreased degradation, which helps in maintaining cell water status, protects membranes and proteins from stress (Kishor and Sreenivasulu, 2014). This has been shown previously in petunias (Yamada et al., 2005). In this study, the proline content in drought-treated plants was higher than that in well-watered plants. After seeds soaked in the strain HX-2 suspension, proline content significantly increased in drought-treated plants. Combined plant biomass changes, these results indicated that strain HX-2 promotes maize seedlings resistance to drought stress may be closely related with increased proline content. Similar studies have reported that Pseudomonas spp. and Azospirillum spp. can help maize seedlings to endure limited water availability (Sandhya et al., 2010; Bano et al., 2013).

Our previous studies also have demonstrated that plant growth-promoting bacteria (PGPR) B. aquimaris DY-3 was likely through the integration of the antioxidant enzymes and the non-antioxidant systems to improve the maize seedling growth under salt stress (Li and Jiang, 2017). It showed that B. megaterium strain HX-2 and B. aquimaris DY-3 were 
likely to improve the plant response to abiotic stress through the similar mechanism, because drought and salinity are both attributed to water deficit of plants.

\section{CONCLUSIONS}

In conclusion, application of Bacillus megaterium strain HX-2, with the characteristics of indole-3-acetic acid (IAA) production and phosphate solubilization, under drought stress and well-watered conditions can improve plant height, root length, root:shoot ratio, biomass, root activity, P content, relative water content, proline content, activities of superoxide dismutase, peroxidase, catalase and ascorbate peroxidase, decrease electrolyte leakage and malondialdehyde content of maize seedlings. These results indicated that $B$. megaterium strain HX-2 plays an important role in improving plant growth and drought tolerance of plants through IAA production and phosphate solubilization to enhance the antioxidant system.

\section{ACKNOWLEDGEMENTS}

The work was supported by the National Natural Science Foundation of China (31601386), Shandong Key Research and Development Plan (Public Welfare Special Project) (2017GNC11103), Shandong Province Higher Educational Science and Technology Program (J18KA121), the National Key Research and Development Program of China (2017YFD0701203), the Research Foundation for Advanced Talents of Qingdao Agricultural University (1113346).

\section{REFERENCES}

Amaresan, N., Jayakumar, V., Kumar, K., and Thajuddin, N. 2012. Isolation and characterization of plant growth promoting endophytic bacteria and their effect on tomato (Lycopersicon esculentum) and chilli (Capsicum annuum) seedling growth. Annals of Microbiology 62:805-810.

Andreote, F.D., Araújo, W.L.D., Azevedo, J.L.D., Elsas, J.D.V., Rocha, U.N.D., and Overbeek, L.S.V. 2009. Endophytic colonization of potato (Solanum tuberosum L.) by a novel competent bacterial endophyte, Pseudomonas putida strain p9, and its effect on associated bacterial communities. Applied Environmental Microbiology 75:3396-3406.

Anjum, S.A., Wang, L., Farooq, M., Khan, I., and Xue, L. 2011. Methyl jasmonate-induced alteration in lipid peroxidation, antioxidative defence system and yield in soybean under drought. Journal Agronomy and Crop Science 197:296-301.

Bano, Q., Ilyas, N., Bano, A., Zafar, N., Akram, A., and Hassan, F.U.L. 2013. Effect of Azospirillum inoculation on maize (Zea mays L.) under drought stress. Pakistan Journal of Botany 45:13-20.

Bao, S.D. 2000. Soil and agricultural chemistry analysis. $3^{\text {rd }}$ ed. China Agriculture Press, Beijing, China [In Chinese].

Cedeño-García, G.A., Gerding, M., Moraga, G., Inostroza, L., Fischer, S., and Sepúlveda-Caamaño, M., et al. 2018. Plant growth promoting rhizobacteria with ACC deaminase activity isolated from Mediterranean dryland areas in Chile: Effects on early nodulation in alfalfa. Chilean Journal of Agricultural Research 78:360-369.

Chen, G.X., and Asada, K. 1992. Inactivation of ascorbate peroxidase by thiols requires hydrogen peroxide. Plant and Cell Physiology 33:117-123.

Daryanto, S., Wang, L., and Jacinthe, P.A. 2016. Global synthesis of drought effects on maize and wheat production. PLOS ONE 11:e0156362.

Devi, S.I., and Momota, P. 2015. Plant-endophyte interaction and its unrelenting contribution towards plant health. Plant Microbes Symbiosis: Applied Facets. Springer, New Delhi, India.

Egorshina, A.A., Khairullin, R.M., Sakhabutdinova, A.R., and Luk'Yantsev, M.A. 2012. Involvement of phytohormones in the development of interaction between wheat seedlings and endophytic Bacillus subtilis, strain 11BM. Russian Journal of Plant Physiology 59:134-140.

Feng, Y., Shen, D., and Song, W. 2006. Rice endophyte Pantoea agglomerans, YS19 promotes host plant growth and affects allocations of host photosynthates. Journal of Applied Microbiology 100:938-945.

Filippou, P., Antoniou, C., and Fotopoulos, V. 2013. The nitric oxide donor sodium nitroprusside regulates polyamine and proline metabolism in leaves of Medicago truncatula plants. Free Radical Biology and Medicine 56:172-183.

Ghahfarokhi, M.G., Mansurifar, S., Taghizadeh-Mehrjardi, R., Saeidi, M., Jamshidi, A.M., and Ghasemi, E. 2015. Effects of drought stress and rewatering on antioxidant systems and relative water content in different growth stages of maize (Zea mays L.) hybrids. Archives of Agronomy and Soil Science 61:493-506.

Hyodo, K., Suzuki, N., Mise, K., and Okuno, T. 2017. Roles of superoxide anion and hydrogen peroxide during replication of two unrelated plant RNA viruses in Nicotiana benthamiana. Plant Signaling \& Behavior 12(6):e1338223. 
Ji, S.H., Gururani, M.A., and Chun, S.C. 2014. Isolation and characterization of plant growth promoting endophytic diazotrophic bacteria from Korean rice cultivars. Microbiological Research 169:83-98.

Kishor, P.B.K., and Sreenivasulu, N. 2014. Is proline accumulation per se, correlated with stress tolerance or is proline homeostasis a more critical issue? Plant Cell and Environment 37:300-311.

Li, H.Q., and Jiang, X.W. 2017. Inoculation with plant growth-promoting bacteria (PGPR) improves salt tolerance of maize seedling. Russian Journal of Plant Physiology 64:235-241.

Li, H.Q., Zhang, L.L., Jiang, X.W., and Liu, Q.Z. 2015. Allelopathic effects of phenolic acids on the growth and physiological characteristics of strawberry plants. Allelopathy Journal 35:61-75.

Mahanty, T., Bhattacharjee, S., Goswami, M., Bhattacharyya, P., Das, B., and Ghosh, A., et al. 2016. Biofertilizers: a potential approach for sustainable agriculture development. Environmental Science and Pollution Research 24:1-21.

Marulanda, A., Barea, J.M., and Azcón, R. 2009. Stimulation of plant growth and drought tolerance by native microorganisms (AM fungi and bacteria) from dry environments: mechanisms related to bacterial effectiveness. Journal of Plant Growth Regulation 28(2):115-124.

Premono, E.M., Moawad, M.A., and Vlek, P.L.G. 1995. Effect of phosphate-solubilizing Pseudomonas putida on the growth of maize and its survival in the rhizosphere. Indonesian Journal of Crop Science 11:13-23.

Rajkumar, M., Ae, N., and Freitas, H. 2009. Endophytic bacteria and their potential to enhance heavy metal phytoextraction. Chemosphere 77:153-160.

Ryan, R.P., Germaine, K., Franks, A., Ryan D.J., and Dowling, D.N. 2008. Bacterial endophytes: recent developments and applications. FEMS Microbiology Letters 278:1-9.

Saia, S., Rappa, V., Ruisi,P.,Abenavoli, M.R.,Sunseri,F., Giambalvo,D.,et al. 2015. Soil inoculation with symbiotic microorganisms promotes plant growth and nutrient transporter genes expression in durum wheat. Frontiers in Plant Science 6:815.

Sandhya, V., Ali, S.Z., Grover, M., Reddy, G., and Venkateswarlu, B. 2010. Effect of plant growth promoting Pseudomonas spp. on compatible solutes, antioxidant status and plant growth of maize under drought stress. Plant Growth Regulation 62:21-30.

Sandhya, V., Ali, S.Z., Grover, M., Reddy, G., and Venkateswarlu, B. 2011. Drought-tolerant plant growth promoting Bacillus spp.: effect on growth, osmolytes, and antioxidant status of maize under drought stress. Journal of Plant Interactions 6:1-14.

Siripornadulsil, S., Traina, S., Verma, D.P., and Sayre, R.T. 2002. Molecular mechanisms of proline-mediated tolerance to toxic heavy metals in transgenic microalgae. Plant Cell 14:2837-2847.

Sun, Q., Liang, X.L., Zhang, D.G., Li, X.H., Hao, Z.F., Weng, J.F., et al. 2017. Trends in drought tolerance in Chinese maize cultivars from the 1950s to the 2000s. Field Crops Research 201:175-183.

Voigt, E.L. 2009. Salt-induced changes in antioxidative enzyme activities in root tissues do not account for the differential salt tolerance of two cowpea cultivars. Brazilian Journal of Plant Physiology 2:113-122.

Vurukonda, S.S.K.P., Vardharajula, S., Shrivastava, M., and Skz, A. 2016. Multifunctional Pseudomonas putida, strain FBKV2 from arid rhizosphere soil and its growth promotional effects on maize under drought stress. Rhizosphere 1:4-13.

$\mathrm{Wu}$, Y., and Cosgrove, D.J. 2000. Adaptation of roots to low water potentials by changes in cell wall extensibility and cell wall proteins. Journal of Experimental Botany 51:1543-1553.

Yamada, M., Morishita, H., Urano, K., Shiozaki, N., Shinozaki, K., and Yoshiba, Y. 2005. Effects of free proline accumulation in petunias under drought stress. Journal of Experimental Botany 56:1975-1981.

Zhang, J. 2004. Risk assessment of drought disaster in the maize-growing region of Songliao Plain, China. Agriculture, Ecosystems \& Environment 102(2):133-153.

Zhang, Y.F., He, L.Y., Chen, Z.J., Wang, Q.Y., Qian, M., and Sheng, X.F. 2011. Characterization of ACC deaminase-producing endophytic bacteria isolated from copper-tolerant plants and their potential in promoting the growth and copper accumulation of brassica napus. Chemosphere 83:57-62.

Zhao, M.R., Han, Y.Y., Feng, Y.N., Li, F., and Wang, W. 2012. Expansins are involved in cell growth mediated by abscisic acid and indole-3-acetic acid under drought stress in wheat. Plant Cell Reports 31:671-685.

Zhu, X., Song, F., and Xu, H. 2010. Influence of arbuscular mycorrhiza on lipid peroxidation and antioxidant enzyme activity of maize plants under temperature stress. Mycorrhiza 20:325-332. 